Conchusions.

1. The results of treating recent experimental wounds opening into the subcutaneous tissue which have been infected with highly virulent diphtheria bacilli prove the efficiency of antiseptic therapy. Under the conditions investigated brief treatment with a suitable antiseptic (neutral acriflavine in concentrations of 1 in 100 to 1 in 1,000 ) has caused survival of practically 100 per cent. of the infected animals. On the other hand, salt solution (either 0.85 or 5 per cent. $\mathrm{NaCl}$ ) similarly applied did not prevent in any instance the acute illness and fatal termination.

2. When acriflavine and carbolic acid are compared, it is found that the ratio of their therapeutic effectiveness exceeds 50 to 1 . This conforms with estimates of their relative potency previously arrived at by $\mathrm{us}^{3}$ by other methods.

3. In less virulent infections the therapeutic action of carbolic acid is evident. But bipp showed practically no action even in the latter; it would appear that the therapeutic effect of this mixture, so frequently commented on by clinical observers, must depend on some property other than an antiseptic one.

1 Braun: Med. Klin, 1920, REFERENCES.

2 Browning and Gulbransen? Journ. 406; Klin. Woch., 1922, 1, p. 761 Browning Gulbransen Kennaway, and Thornton., 1919, 22, p. 265 Journal, 1917, i, p. 73 ; ii, p. 70 ; see also Browning's Applied Bacterio logy, London, 1918, p. 65. - Feiler : Deut. Zeit. f. Chir., 1921, 164, p. 379 ' Reinhardt: Zeit. t. Hyg. u. Inf., 1922, 95, p. 1. '6 Watson Cheyne, Bassett-Smith, and Edmunds; see "Watson Cheyne, Lancet, February 27th, 1915.

\section{THE DECLINE OF LITHOLAPAXY.}

\section{$\mathrm{BY}$}

\section{ALFRED HOOTON, C.I.E., M.R.C.S., L.R.C.P., MaJor-General I.M.S., Poona, India.}

IN the Principles and Practice of Surgery (1914), by Dr. A. P. C. Ashhurst, the following passage occurs:

"The operation of litholapaxy is not now in general use because the mortality of cutting operations is less than when Bigelow's operation was introduced, and because recurrence of stome forma tion is frequent (18 per cent.), either because all the fragments are not removed at first, or because urinary obstruction or vesical infection are not relieved. But the primary mortality is very low ( 5 per cent.), and the operation may be done under local anaesthesia in very debilitated subjects. It is best reserved for such thesia in very debilitated subjects. It , is

The book is an American one, and, though presumably representative of practice in the United States, does not necessarily speak for British surgery. But this is, in any case, strange doctrine for the country of Bigelow, and there is reason to believe that the same view is gaining ground amongst British surgeons. A short time ago, for instance, I met a keen and highly qualified junior surgeon in charge of an Indian hospital, who was doing no crushing, and told me that the operation of litholapaxy was now regarded as obsolete at home. He had spent several years in resident appointments at well known English hospitals; and one is continually hearing the same view from men who have recently passed through British medical schools. It is for this reason that $I$ have thought it worth while to write the following note.

Thirty years ago my old chief, Mr. F. A. Southam, was using lithotrites successfully in the Manchester Royal Infirmary, and there was no doubt in those days, so far as I remember, as to litholapaxy being the operation of choice for stone in the bladder. The chief arguments now brought against it appear to be that suprapubic lithotomy can be done with nearly as great safety, that litholapaxy is difficult to learn and dangerous when performed by inexperienced operators, and that there are more recurrences after it than after lithotomy.

A statistical comparison of the results of the two operations is hardly possible in India, where for the most part only the bad cases are dealt with by the cutting operation, and I have never seen an effective comparison of British figures, which might presumably be obtainable. The impression is widely prevalent in India, however, that litholapaxy in skilled hands is much tho less dangerous opera- tion, and our figures speak for themselves, and still more emphatically if it is admitted, as we all contend, that, contrary to the impression at home, our cases on the average are far less promising than those which come to the English hospitals. We have a very large proportion of large stones and septic bladders to deal with, and we consider, moreover, that the idea which seems to prevail at home that Indian patients in general bear operation better than Europeans is entirely erroneous. It remains to be said that suprapubic lithotomy is not without its dangers. A very little disturbance of the cave of Retzius may lead, to disastrous consequences.

The frequency of recurrence after litholapaxy is much exaggerated. Under proper conditions recurrences should be very rare. Experience of $m y$ own and other people's work is that they are quite infrequent, though it is unfortunately impossible to put up figures in proof of this statement. A fair test of the general result of the operation is its reputation with the public. The Indian cultivator, who furnishes the great majority of our up-country patients, is an acute judge of the practical results of surgery, as shown, for instance, in his appreciation of Bassini's operation for hernia. As regards litholapaxy, he made up his mind long ago, and there is no surer way of emptying one's hospital than by reverting to a cutting operation where crushing has formerly been in vogue. There is not only the escape from the knife but the early discharge from hospital to be considered, and it is, of course, quite common for children who have been relieved of small stones by the lithotrite in the morning to be rumning about in the afternoon. It is, I think one may say, the opinion of an overwhelming majority of Indian surgeons that litholapaxy in proper hands has great advantages over any of the cutting operations in all but a small percentage of complicated cases, and it would be a very great pity if the contrary view were to be generally accepted and taught in the British schools, particularly in the case of men who are destined to practise in the East. I append a list of cases treated in four representative hospitals of this Presidency. Many more extensive series have appeared in the pages of the British Medical Journal, but they seem to have passed too readily into oblivion.

I.- Cases operated on by Lieut.-Colonel R. W. Anthony, F.R.C.S.E., during three years and three months in 1920-23 at the Civil Hospital at Hyderabad, Sind.

$$
\begin{array}{lcccccc}
\text { Litholapaxy (including } & 30 & \text { perineal } & \text { Cases. } & & \multicolumn{2}{c}{\text { Deaths. }} \\
\text { litholapaxies) } & \ldots & \ldots & \ldots & 1,253 & \ldots . . & 7^{*} \\
\text { Suprapubic lithotomy } & \ldots & \ldots & 11 & \ldots . . . & 3 \\
\text { Perineal lithotomy } & \ldots & \ldots & 0 & \ldots \ldots . & 0 \\
\text { * Three others "discharged } & \text { otherwise } & \text { "-probably } & \text { died. }
\end{array}
$$

This is the most noted centre for vesical calculus in this Presidency, and has dealt with an average of 464 cases a year during the last ten years. Colonel Anthony says that he looks on every case of stone as one for litholapaxy if it can be done, and that there are very few cases in which it cannot, given an expe rienced operator. If it is impossible to crush by the urethra in the ordinary way he perform perineal litholapary. the ordinary way he performs perineal litholapaxy. He cannot deal with, either by the ordinary or perineal route, by means of a large lithotrite or a hammer. He apparently never does perineal lithotomy now, and only performs suprapubic lithotomy primarily from choice in patients with enlarged prostates. Thus, as he points out, his suprapubic cases must be taken largely as failed litholapaxies of a complicated nature-for example, cases in which the bladder has an hour-glass shape, or processes like the rare accidents where the lithotrite has jammed, or perforation of rare accidents where the lithotrite has
the bladder has accidentally occurred.

II.-Cases operated on by Lieut.-Colonel T. S. Novis, F.R.C.S., at the Jamsetjee Jeejeebhoy Hospital, Bombay, from June 14th, 1920, to December 31st, 1923.

$$
\begin{array}{ccccccc}
\text { Litholapaxy } & & \multicolumn{3}{c}{\text { Cases. }} & \multicolumn{2}{c}{\text { Deaths. }} \\
\text { Perineal litholapaxy } & \ldots & \ldots & 114 & \ldots \ldots . & 1 \\
\text { Suprapubic lithotomy } & \ldots & \ldots & 0 & \ldots \ldots . & 0 \\
\text { Perineal lithotomy } \ldots & \ldots & \ldots & 17 & \ldots \ldots . & 5 \\
\text { Note.-Of the deaths from suprapubic } & \ldots & \ldots & 2 & \ldots . . & 0 \\
\text { lithotomy, } & \text { two } & \text { were complicated }
\end{array}
$$
prostatectomy, and two developed pneumonia.

This is the chief general hospital in Bombay, and associated with the Grant Medical College. Here, also; litholapaxy is the routine operation, the contraindications quoted by Colonel Novis being very large or very hard stones, very soft putty-like stones, stricture, enlarged prostate, extensive kidney disease, and bladder growth of any considerable size. He lays stress on a routine cystoscopic examination of the bladder, both before operation, to cystoscopic examination of the bladder, both before operation, to
exclude the possibility of encystment of the stone or other comexclude the possibility of encystment of the stone or other com-
plications, and immediately after, or at any rate before discharge, 
to make sure no fragment is left behind. The series quoted includes two cases of haemorrhage, in both of which suprapubic cystotomy found to exist. Both these recovered. Here also the suprapubic cases are thre worst and cannot be quoted for purposes of comparison.

III.-Cases operated on by Mr. A. K. Dalal, F.R.C.S., also at the Jamsetjee Jeejeebhoy Hospital, from November 29th, 1921, to March 22nd, 1924.

$$
\begin{array}{lllrrr} 
& & \multicolumn{3}{c}{\text { Cases. }} & \multicolumn{2}{c}{\text { Death }} \\
\text { Litholapaxy } & \ldots & \ldots & 13 & \ldots \ldots . & 0 \\
\text { Suprapubic lithotomy } & \ldots & \ldots & 8 & \ldots \ldots . & 0 \\
\text { Perineal lithotomy ... } & \ldots & \ldots & 1 & \ldots \ldots . & 0
\end{array}
$$

IV.-Cases operated on by Lieut.-Colonel A. J. Vernon Betts, M.B., at the Civil Hospital, Nasik, from November 1st, 1922, to October 31st, 1923.

\section{Litholapax}

Perineal litholapaxy

Suprapubic lithotomy

Perineal lithotomy...
This is taken as a typical civil hospital with a fairly active surgical practice The series is a small one because these are the only results for which he can personally vouch.

V.-Cases operated on by Lieut.-Colonel A. Hooton, I.M.S., at the Agency Hospital, Rajkot, from December 5th, 1920, to March $23 \mathrm{rd}, 1923$

\section{Litholapaxy \\ Perineal litholapaxy \\ Suprapubic lithotom}

Perineal lithotomy...

$$
\begin{array}{crrrr} 
& & \text { Cases. } & & \text { Deaths. } \\
\ldots & \ldots & 94 & \ldots \ldots . & 2 \\
\ldots . & \ldots & 5 & \ldots \ldots . & 0 \\
\ldots & \ldots & 15 & \ldots \ldots . & 0 \\
\ldots & \ldots & 1 & \ldots \ldots & 1
\end{array}
$$

This also is taken as a typical civil hospital with a fairly active surgical practice.

Perineal lithotomy still has its uses (contrary to the dictum of some of the textbooks), though the occasions are not frequent. Encysted stones, or abscess associated with them, about the neck of the bladder, call for one or other of the perineal operations.

\section{A METHOD OF DETERMINING THE PATENCY OF THE FALLOPIAN TUBES BY $X$ RAYS.

\author{
BY
}

EVERARD WILLIAMS, M.D., M.R.C.P. OBSTETRIC REGISTRAR AND TUTOR,

AND

RUSSELL REYNOIDS, M.B.,

PHYSICIAN IN CHARGE, DEPARTMENT OF RADIOLOGY AND ELECTROTHERAPEUTICS,

CHARING CROSS hospital.

ThE investigation of certain cases of sterility involves an examination of the Fallopian tubes in order to ascertain whether they are patent. It was felt that the present

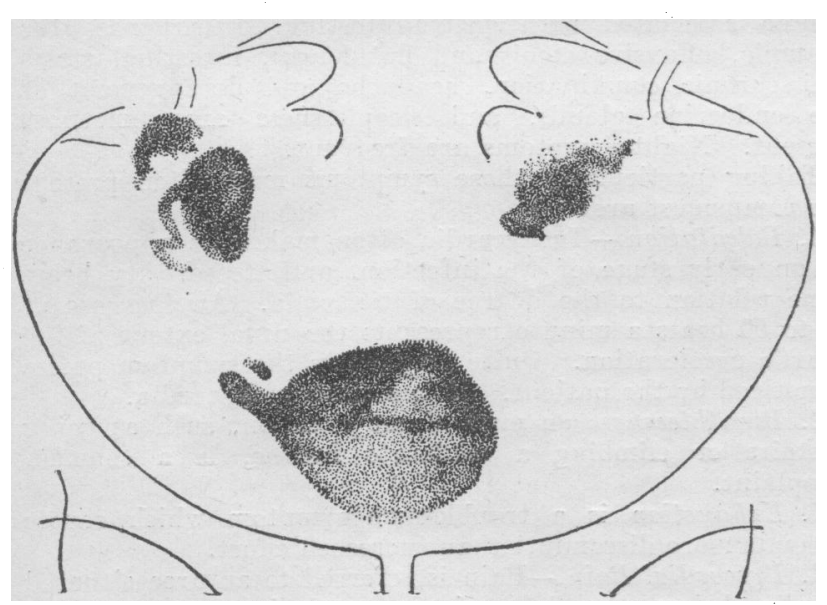

FIG. 1.-Shows shadow in uterine cavity and distal portions of tubes and timbriated extremities. (A normal case.)

methods of testing this patency are unsatisfactory, in that they are all open to the objection of causing an increased intrauterine and intratubal pressure, in cases in which, from their very nature, it is anticipated that organisms may be lurking in the uterus or the tubes, and that it would therefore be safer to employ some method of investigation which does not depend upon creating a positive intrauterine or intratubal pressure.

A method suggested itself to one of us (E. W.) after reading of Bond's experiment of the recovery, at a laparotomy, of coloured particles from the peritoneal cavity of rabbits, after their previous introduction into the vagina. If particles opaque to $x$ rays be substituted for coloured particles, a radiogram should indicate their passage through the tube. A method was tried in which particles of barium sulphate were insufflated into the cervix uteri, and $x$-ray photographs were taken twenty-four, forty-eight, and seventy-two hours later. Several cases of normal multiparous women were thus investigated. The photographs did not give a shadow sufficiently dense to be really savisfactory, and at Dr. Russell Reynolds's suggestion an emulsion of barium sulphate was tried, and gave good results, particularly when general anaesthesia was employed
(Figs. 1 and 2). A simple apparatus (made by Allen and Hanburys) was devised for the introduction of bismuth or barium emulsion into the uterine cavity (Fig 3 ). The point we wish to emphasize is that the emulsion is merely dropped into the uterine cavity and is not forced in under pressure. An anaesthetic is not necessary.

The question how the particles find their way into the tubes naturally arises. The observations that better shadows are obtained if the patient has had an anaesthetic (with the accompanying post-anaesthetic retching and vomiting), and that Bond placed the particles in the vagina and not in the uterus, suggested the possibility of aspiration being the motive power, though the original conception was that the ciliated epithelium swept the particles up. To settle the point certain experiments

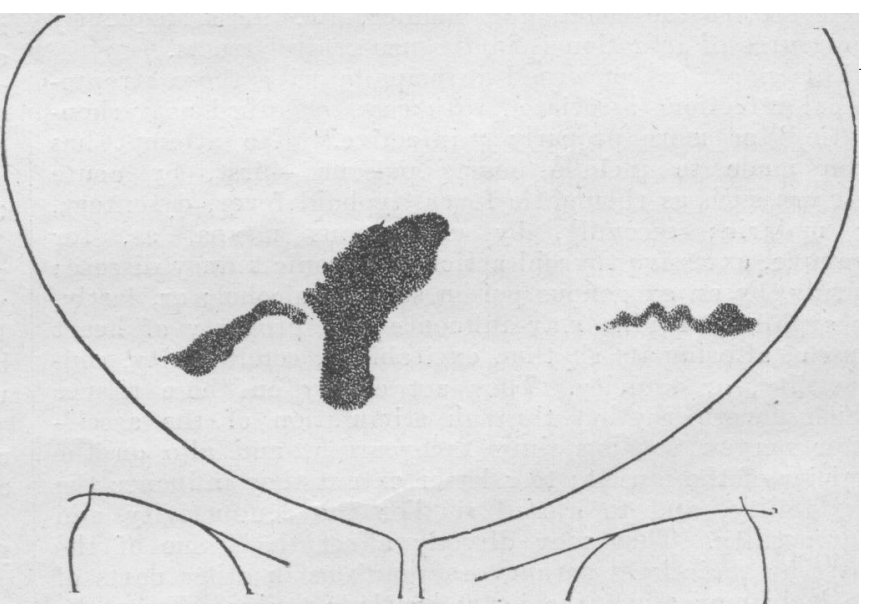

FIG. 2-Shows shadows similar to Fig. 1. A normal case, ten hours after barium introduction

were performed upon animals in which bismuth emulsion was introduced into the vagina alternately with and without ligature of the Fallopian tubes.

These experiments showed that the particles do not find their way up the Fallopian tubes unless there is a free communication between the tube and the peritoneal cavity. This suggests that a purely mechanical factor, such as aspiration, is more likely to be responsible than anything in the nature of ciliary activity. If the tubal ostia are patent, the emulsion travels from the uterus to the tube, and therefore, if the shadow is seen in the tube at all, it indicates patency of that tube. In the course of seventy-two hours the whole of the bismuth or barium has disappeared. In no instance have

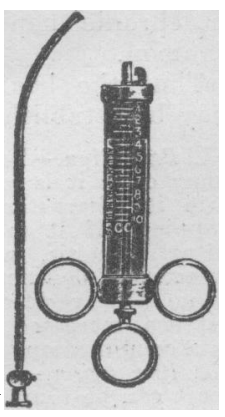
any after-effects been complained of by the patients.

Another point worthy of mention is that the shadow in the body of the uterus gives a much more accurate estimation of the size of the uterine cavity, in cases of infantilo uterus or other maldevelopment, than does bimanual 